\title{
Granules for Oral Suspension in Sachet
}

National Cancer Institute

\section{Source}

National Cancer Institute. Granules for Oral Suspension in Sachet. NCI Thesaurus. Code C149549.

Medicinal product consisting of granules for oral suspension presented in a sachet. 